\title{
Potential Role of Flavobacterial Gliding-Motility and Type IX Secretion System Complex in Root Colonization and Plant Defense
}

\author{
Max Kolton, ${ }^{1,2}$ Omer Frenkel, ${ }^{3}$ Yigal Elad, ${ }^{3}$ and Eddie Cytryn ${ }^{1}$ \\ ${ }^{1}$ Institute of Soil, Water and Environmental Sciences, The Volcani Center, Agricultural Research Organization, Bet Dagan, \\ Israel; ${ }^{2}$ Department of Plant Pathology and Microbiology, The Robert H. Smith Faculty of Agriculture, Food and Environment, \\ The Hebrew University of Jerusalem, Rehovot, Israel; and ${ }^{3}$ Department of Plant Pathology and Weed Research, The Volcani \\ Center, Agricultural Research Organization
}

Submitted 6 March 2014. Accepted 22 May 2014.

\begin{abstract}
Members of the Flavobacterium genus are often highly abundant in the rhizosphere. Nevertheless, the physiological characteristics associated with their enhanced rhizosphere competence are currently an enigma. Flavobacteria possess a unique gliding-motility complex that is tightly associated with a recently characterized Bacteroidetes-specific type IX protein secretion system, which distinguishes them from the rest of the rhizosphere microbiome. We hypothesize that proper functionality of this complex may confer a competitive advantage in the rhizosphere. To test this hypothesis, we constructed mutant and complement root-associated flavobacterial variants with dysfunctional secretion and gliding motility, and tested them in a series of in planta experiments. These mutants demonstrated significantly lower rhizosphere persistence (approximately 10-fold), plant root colonization (approximately fivefold), and seed adhesion capacity (approximately sevenfold) than the wild-type strains. Furthermore, the biocontrol capacity of the mutant strain toward foliar-applied Clavibacter michiganensis was significantly impaired relative to the wild-type strain, suggesting a role of the gliding and secretion complex in plant protection. Collectively, these results provide an initial link between the high abundance of flavobacteria in the rhizosphere and their unique physiology, indicating that the flavobacterial gliding-motility and secretion complex may play a central role in root colonization and plant defense.
\end{abstract}

The rhizosphere is the soil environment that is directly influenced by the presence and activities of plant roots. This nutrientrich ecosystem is characterized by higher microbial biomass and activity relative to the surrounding bulk soil (Dennis et al. 2010). There is increasing evidence that microbial communities in the rhizosphere have direct and indirect effects on plant protection and productivity (Berendsen et al. 2012; Mendes et al. 2013); however, the physiological characteristics of individual members of these communities and their role in plant-microbe interactions is still not well understood. Rhizosphere competence is

Corresponding author: E. Cytryn; E-mail: Eddie@volcani.agri.gov.il

* The $e$-Xtra logo stands for "electronic extra" and indicates that one supplementary figure is published online.

(C) 2014 The American Phytopathological Society used to define physiological traits that allow plant-root-associated bacteria to effectively colonize root surfaces, compete for nutrients, and propagate in the highly competitive rhizosphere environment (Ahmad and Baker 1987). These traits include motility, biofilm formation, secretion of plant-polymer-degrading enzymes, and synthesis of secondary metabolites (Barret et al. 2011; Lugtenberg and Kamilova 2009; Sessitsch et al. 2012). It has been previously demonstrated that effective root colonization by certain rhizosphere bacteria can reduce pathogen interaction with plant roots and stimulate plant defense systems, resulting in disease suppression (Haggag and Timmusk 2008; Mendes et al. 2011, 2013).

Culture-dependent and independent analyses of root-associated bacterial communities have determined that members of the Bacteroidetes phylum, especially those belonging to the Flavobacterium genus, are often highly abundant in the rhizosphere of a wide array of plants, where they may compose up to $20 \%$ of the total defined bacterial genera (Bodenhausen et al. 2013; Bulgarelli et al. 2012; Johansen and Binnerup 2002; Kolton et al. 2011; Lundberg et al. 2012; Manter et al. 2010; Schlaeppi et al. 2014). Flavobacteria are well known for their capacity to utilize poorly degradable macromolecules (Shipman et al. 2000; Xu et al. 2003), and have been associated with the degradation of bacteria, fungi, insects, and nematode constituents in the rhizosphere (Bernardet and Bowman 2006; Peterson et al. 2006). Recently, comparative genomic analysis revealed that flavobacteria isolated from soil and the rhizosphere harbor an arsenal of extracellular macromolecular-degrading enzymes such as peptidases, chitinases, and several glycoside hydrolases that are specifically linked to plant cell wall metabolism, which may support their survival in the rhizosphere (Kolton et al. 2014). Although flavobacterial strains are not traditionally associated with biocontrol, several studies have demonstrated that their abundance in the rhizosphere is positively correlated to plant biomass accumulation (Manter et al. 2010) and resistance to pathogens (Alexander and Stewart 2001; Gunasinghe and Karunaratne 2009; Hebbar et al. 1991; Sang and Kim 2012; Sang et al. 2008).

Flavobacteria contain a unique Bacteroidetes-specific gliding-motility complex that enables rapid gliding movement over solid surfaces (Jarrell and McBride 2008; McBride 2004; Nakane et al. 2013), distinguishing them from the rest of the rhizosphere microbiome. Previous studies conducted with the model strain Flavobacterium johnsoniae revealed that the gliding-motility complex is tightly associated with the type IX secretion system (T9SS) that is responsible for the secretion of 
extracellular hydrolytic enzymes such a chitinases and proteases (McBride and Zhu 2013; Nakane et al. 2013; Sato et al. 2010). The lipoprotein GldJ stabilizes the interaction between the T9SS and gliding-motility-associated proteins, and its disruption in the model strain $F$. johnsoniae almost completely abolishes both gliding-motility and chitinase secretion (Braun and McBride 2005). Furthermore, the T9SS is responsible for secretion of the surface motility proteins SprB and RemA, which are required for gliding motility (Nakane et al. 2013; Nelson et al. 2008; Shrivastava et al. 2013).

Clavibacter michiganensis subsp. michiganensis is the causal agent of bacterial wilt and canker in tomato (Solanum lycopersicum) (Eichenlaub and Gartemann 2011). Generally, C. michiganensis causes systemic infection of tomato plants but it can also cause spots on leaves as a result of a local infection (Carlton et al. 1998). Due to high tolerance to desiccation and low temperatures $C$. michiganensis may survive in soil and greenhouse equipment for years (Werner et al. 2002) and, under suitable conditions, dormant communities can rapidly proliferate (Carlton et al. 1998), resulting in significant economic losses. Currently, only a limited number of agrotechnical and plant-directed treatments are available for reduction and control of Clavibacter spp. and, therefore, additional methods are urgently needed (Eichenlaub and Gartemann 2011).

In this study, we comprehensively assessed the role of the flavobacterial gliding-motility-T9SS complex in seed and root colonization, rhizosphere persistence, and stimulation of plant defense toward the tomato pathogen $C$. michiganensis, using the root-associated Flavobacterium sp. strain F52 (Kolton et al. 2012,2014 ) as a model strain for assessing these flavobacteriaplant interactions. Our results strongly support the hypothesis that gliding-motility or secretion of extracellular enzymes by the T9SS are associated with flavobacterial rhizosphere competence.

\section{RESULTS}

Phenotypic evaluation of mutant and complemented gliding and secretion-deficient strains.

Construction of gliding and secretion-deficient ( $g l d J$ ) mutant and complement Flavobacterium sp. strain F52 strains is de- scribed in detail below. Briefly, a chimeric gldJ fragment was cloned into the Bacteroidetes suicide vector pLYL001 to generate pF52JHim (Fig. 1A), which was introduced into Flavobacterium sp. strain F52 by triparental mating, as previously described (McBride and Kempf 1996). Disruption of gldJ was verified by polymerase chain reaction (PCR) amplification and sequencing of the chimeric fragment and by whole-genome sequencing of the mutant gldJ strain (data not shown). For complementation studies, a 2,077-bp PCR product was ligated into the pCP11 plasmid to generate p11F52GldJ (Fig. 1B). Disruption of gldJ did not significantly affect bacterial growth but transformation of Flavobacterium sp. strain F52 with pCP11 and p11F52GldJ resulted in a significant increase in generation time in casitone yeast extract (CYE) medium at all temperatures tested $\left(20,25\right.$, and $\left.30^{\circ} \mathrm{C}\right)$ in the presence and absence of erythromycin (Supplementary Fig. S1). The gldJ mutants displayed significant motility defects (Fig. 2A) and failed to form clearing zones on agar plates amended with colloidal chitin (Fig. 2B). However, gliding motility and chitin degradation were almost fully restored to wild-type (WT) levels in mutants complemented with p1152GldJ (Fig. 2A and B). Furthermore, disruption of gldJ resulted in resistance of the mutant Flavobacterium F52 strains toward $\varphi C j 1, \varphi C j 13$, $\varphi C j 23, \varphi C j 28, \varphi C j 29, \varphi C j 42, \varphi C j 48$, and $\varphi C j 54$ bacteriophages, and complementation with p1152GldJ restored sensitivity (Fig. 2C), similar to previous observations in F. johnsoniae (Braun and McBride 2005).

\section{Effect of gldJ disruption on seed adhesion.}

The effect of gliding-motility-T9SS complex inactivation on the capacity of flavobacteria to colonize tomato seed surfaces was evaluated by inoculating surface-sterilized tomato seeds in WT, $\Delta g l d J$, and complement Flavobacterium F52 cell suspensions (approximately $7 \times 10^{8}$ cells $/ \mathrm{ml}$ ) for $10 \mathrm{~min}$ and washing at three different intensity levels to remove weakly adhering cells (below). Adhesion of flavobacterial cells to the tomato seeds significantly decreased as a result of the gldJ disruption $(8.5 \pm 1.1$ fold) for all of the washing intensities tested (Fig. 3). At low intensity, the seed colonization capacity of the gldJcomplemented mutants was identical to that of the Flavobacterium F52 WT strains $(4.35 \pm 0.22$ versus $4.31 \pm 0.49$
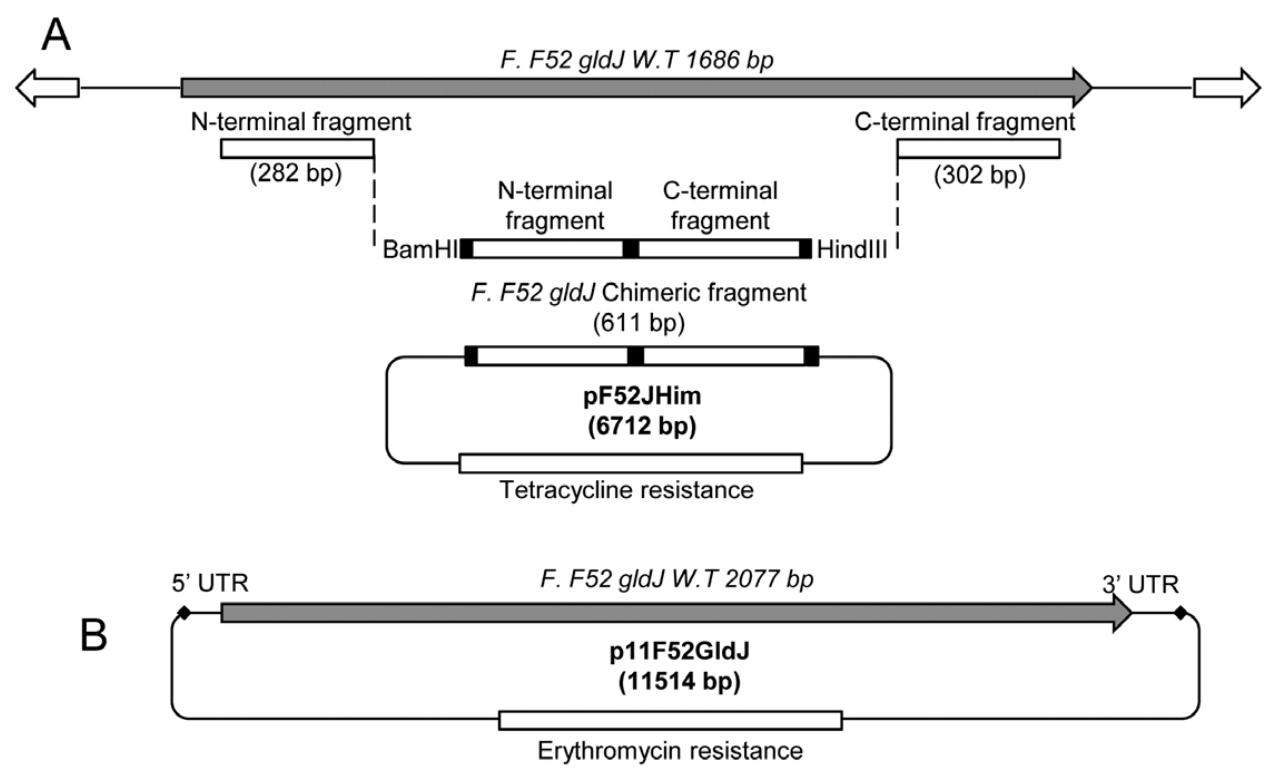

Fig. 1. Genomic map of gld $J$ region and plasmids constructs. A, The chimeric DNA fragment carrying N-and C-terminal fragments of gld $J$ was inserted into pLY001 to generate pF52JHim that was used to generate gliding-motility-type IX secretion system defective strains. Black segments indicate stop codons. B, The nondisrupted DNA gldJ region was inserted into pCP11 to generate p11F52GldJ that was used in complementation studies. 
$\log [\mathrm{CFU} /$ seed $]$ ). Under higher washing intensities, gldJ complementation resulted in average seed surface colonization levels that were higher than mutant values but lower than WT values, suggesting partial restoration of the seed surface colonization capacity (Fig. 3). Nonetheless, due to variation, these values were not statistically significant from either mutants or WT strains and, therefore, the capacity of the complemented strain in the context of this experiment cannot be validated.

\section{Effect of gldJ disruption on seedling colonization.}

Root colonization by soil bacteria is considered to be imperative for stimulating plant growth and defense (RodriguezNavarro et al. 2007), although, in certain cases, volatile compounds such as 2,3-butanediol, secreted by Bacillus strains, can stimulate plant defense systems without being directly associated with root surfaces (Choudhary and Johri 2009; Ryu et al. 2004). Root colonization is dependent on the ability of bacteria to coordinate their motility toward plant chemo-attractants (Espinosa-Urgel et al. 2002). The abundance of Flavobacterium F52 strains (WT, gldJ mutant, and complement) on tomato seedling roots was evaluated 14 days after planting surface-sterilized seed in order to assess the role of the gliding-motility-T9SS complex in root colonization. All three strains were able to colonize tomato seedling root surfaces but the colonization capacity of the WT strains was significantly higher than the gld $J$ mutants $(8.25 \pm 0.12$ versus $7.61 \pm 0.17 \log [\mathrm{CFU} / \mathrm{g}$ of root $])$ at 14 days after seed germination (Fig. 4). The p11F52GldJ-complemented gldJ strain only partially restored seedling root surface colonization $(7.85 \pm 0.18 \log [\mathrm{CFU} / \mathrm{g}$ of root] $)$ (Fig. 4). Similar to the seed adhesion experiments (Fig. 3), the complemented strain showed a response that was between that of the mutant and the WT.
Effect of gldJ disruption on root surface persistence.

Efficient root colonization and persistence is a prerequisite for rhizosphere competent bacteria (Compant et al. 2010; Lugtenberg and Kamilova 2009). Therefore, we evaluated the capacity of Flavobacterium F52 (WT, gldJ mutant, and complement) strains to persist on tomato roots following seedling inoculation, over 21 days postplanting at selected time intervals. All three strains were able to colonize the tomato roots; however, persistence of the WT strain was significantly higher than both the gldJ mutant and the p11F52GldJ complemented strain for all of the analyzed sampling points $(7,14$, and 21 days) (Fig. 5). Although the abundance of the WT strains on the root surfaces decreased by approximately ninefold over the 2 -week growth period, the reduction in the abundance of gldJ mutant strains was approximately 20 -fold (Fig. 5). Due to biological variation in the persistence of the p11F52GldJ complement strain on the tomato roots, the average values were not statistically significant from either mutants or WT strains. We conclude that only partial restoration of root persistence occurred, similar to the phenomenon observed for the previously described experiments (Figs. 3 and 4). The most dramatic reductions in abundance of mutant and complement strains were observed between 7 and 14 days after initial inoculation whereas, in the WT-inoculated plants, this reduction occurred 1 week later (Fig. 5).

\section{Effect of $g l d J$ disruption on plant resistance.}

Some root-associated bacteria stimulate plant defense systems, leading to enhanced resistance toward phytopathogen infection (Compant et al. 2010). In order to assess the potential role of the flavobacterial gliding-motility-T9SS complex in stimulation of plant defense, the gram-positive plant pathogen C. michiganensis was applied to the tomato canopy following

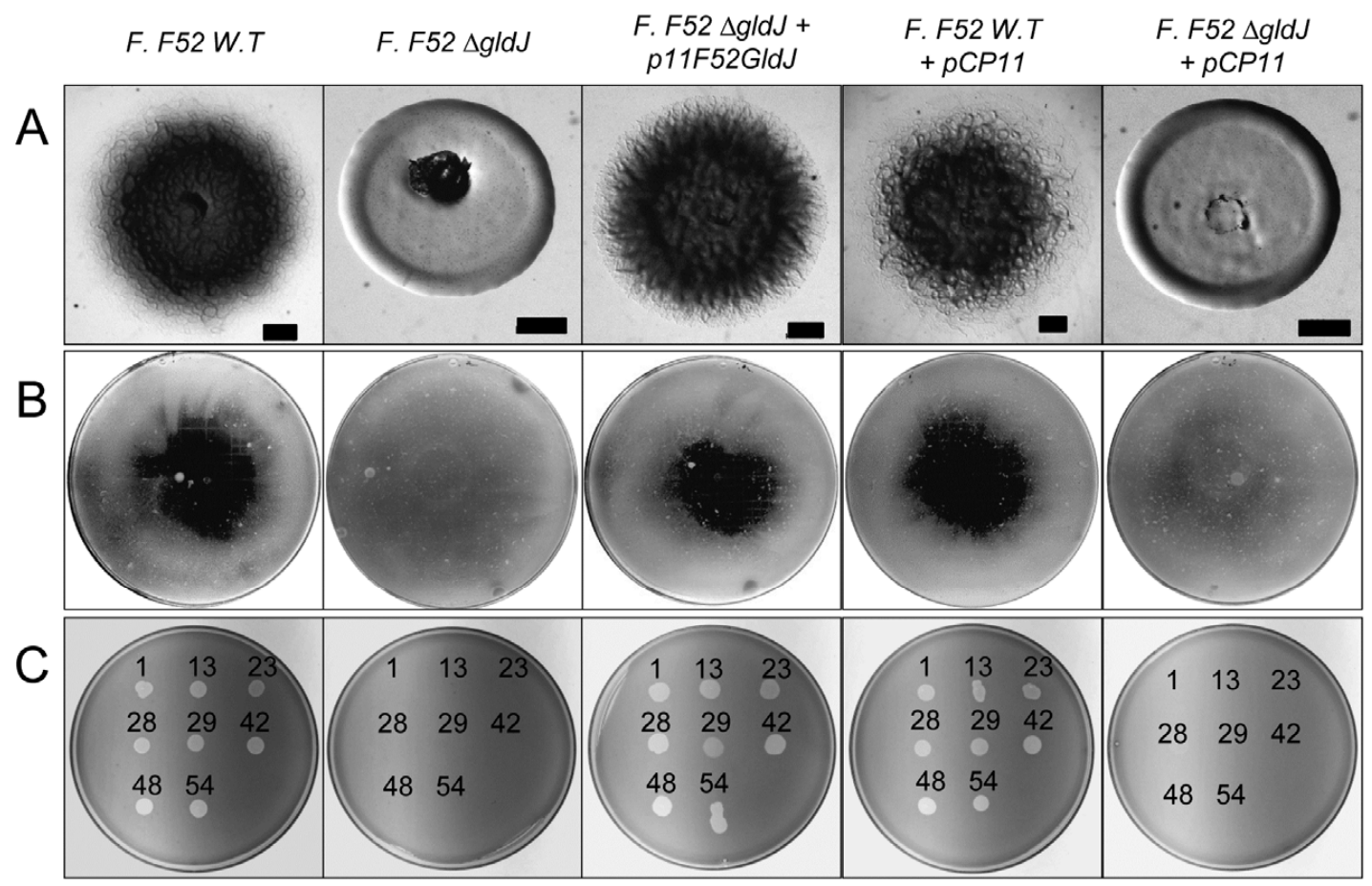

Fig. 2. Effect of gld $J$ disruption on flavobacterial phenotypic characteristics. A, Gliding motility; approximately $10^{7}$ cells were spotted on PY2 agar medium and incubated at $30^{\circ} \mathrm{C}$ for 24 to $48 \mathrm{~h}$. Photomicrographs were taken with a Nikon DS-Fil CCD camera mounted on a Leica MZFLIII stereomicroscope. B, Chitin utilization; approximately $10^{7}$ cells were spotted on PY2 agar medium overlaid with $2 \%$ chitin slurry and were incubated at $30^{\circ} \mathrm{C}$ for 48 to $72 \mathrm{~h}$. The clearing zone on agar plates indicates chitin utilization. C, Bacteriophage resistance; bacteriophages $\left(5 \mu l\right.$ of lysates containing approximately $6 \times 10^{7}$ phage $/ \mathrm{ml}$ ) were spotted onto lawns of cells in casitone yeast extract overlay agar. The plates were incubated at $25^{\circ} \mathrm{C}$ for $24 \mathrm{~h}$ until lysis was observed. Bacteriophages were spotted in the following order, from left to right: top row, $\varphi \mathrm{Cj} 1, \varphi \mathrm{Cj} 13$, and $\varphi \mathrm{Cj} 23$; middle row, $\varphi \mathrm{Cj} 28, \varphi \mathrm{Cj} 29$, and $\varphi \mathrm{Cj} 42$; bottom row, $\varphi \mathrm{Cj} 48$ and $\varphi \mathrm{Cj} 54$. Diameter of the petri dish was $9 \mathrm{~cm} . \mathrm{Bar}=1 \mathrm{~mm}$. 
inoculation of tomato roots with Flavobacterium sp. strain F52 (WT, gldJ mutant, and complement) strains. Both WT and gldJ mutant strain inoculation resulted in increased resistance of the tomato plants toward $C$. michiganensis. However, whereas the mutant strains reduced the level of disease severity (relative to the control treatment of water) by $19.7 \pm 3.9 \%$ (equal to the reduction observed for Escherichia coli $\mathrm{DH} 5 \alpha$ ), the Flavobacterium sp. strain F52 WT strain reduced disease severity levels by $50 \pm 4.2 \%$ (Fig. 6). As observed in the previously described experiments, the reduction in disease severity in plants inoculated with the p11F52GldJ complemented strains $(40.2 \pm 2.1 \%)$ was between values acquired from the gldJ mutant and WT inoculants (Fig. 6).

\section{DISCUSSION}

Root-associated bacterial communities have both direct and indirect effects on plant protection and productivity (Berendsen et al. 2012; Dennis et al. 2010; Mendes et al. 2013); therefore, understanding the physiology of individual bacterial community members is vital for ensuring plant health. Recently conducted next-generation sequencing-based studies have clearly demonstrated that Flavobacterium spp. are a prime constituent of the core rhizosphere microbiome of Arabidopsis and other crops and that they are highly enriched on root surfaces relative to rhizosphere and bulk soil (Bodenhausen et al. 2013; Bulgarelli et al. 2012; Kolton et al. 2011; Lundberg et al. 2012; Manter et al. 2010; Schlaeppi et al. 2014). Furthermore, previous experiments conducted in our lab and by others have suggested that certain flavobacterial strains may be linked to plant protection and productivity (Alexander and Stewart 2001; Gunasinghe and Karunaratne 2009; Hebbar et al. 1991; Manter et al. 2010; Sang and Kim 2012; Sang et al. 2008). Despite their potential importance, a molecular and physiological

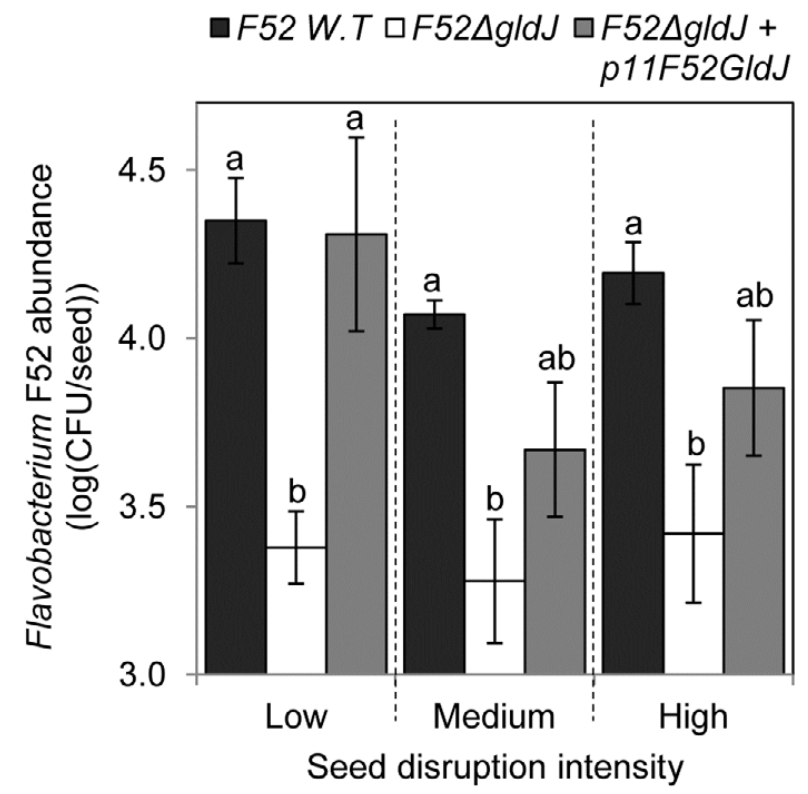

Fig. 3. Effect of gldJ disruption on attachment of cells to tomato seeds. Seed were immersed in bacteria suspension of approximately $10^{8}$ cells $/ \mathrm{ml}$ for $10 \mathrm{~min}$ and washed at three different intensity levels. Then, 10-fold serial dilutions of bacteria dislodged from seed were transferred to casitone yeast extract agar plates with erythromycin $(100 \mu \mathrm{g} / \mathrm{ml})$. Triplicates of five independent experiments were performed. The statistical analysis was done by one-way analysis of variance with the Tukey-Kramer honestly significant difference test. Columns in each seed group followed by a different letter are significantly different $(P<0.05)$. Error bars represent the standard error of the mean of five independent experiments. mechanism that may explain the high prevalence of flavobacteria on and adjacent to root surfaces is still missing.

The unique flavobacterial gliding-motility complex that enables rapid movement over solid surfaces (Jarrell and McBride 2008; McBride 2004; Nakane et al. 2013), is tightly associated with the Bacteroidetes-specific T9SS (McBride and Zhu 2013; Nakane et al. 2013; Sato et al. 2010). To date, most of the studies on flavobacterial gliding-motility and T9SS have focused on understanding genetic organization and biochemical characteristics under laboratory conditions (Agarwal et al. 1997; Braun and McBride 2005; Hunnicutt and McBride 2000; McBride et al. 2003; Nelson et al. 2008; Rhodes et al. 2010; Shrivastava et al. 2013). Here, we expand these studies and explore the ecological role of this unique gliding-motilityT9SS complex, specifically focusing on flavobacteria-plant interactions. We established dysfunctional secretion and gliding-motility mutant lines in the previously characterized root isolate Flavobacterium sp. strain F52 (Kolton et al. 2012, 2014) and conducted a series of in planta experiments.

The gene encoding for gldJ was originally discovered as a lipoprotein required for $F$. johnsoniae gliding motility and chitinase secretion (Braun and McBride 2005). In this study, we confirmed that the gldJ ortholog is also obligatory for both gliding motility and chitinase secretion in Flavobacterium sp. strain F52 (Fig. 2). High sequence and function similarity of the two orthologs supported by reciprocal complementation of the gldJ mutant with either the native or the $F$. johnsoniae gene (data not shown) and it presence in almost all currently characterized flavobacterial stains (McBride and Zhu 2013) suggest that it is evolutionarily conserved and plays a crucial role in the gliding-motility-T9SS complex. Prolonged generation time of the WT relative to the mutant strain in liquid media may be explained by high energy demands of the gliding-motility-T9SS complex. These energy requirements may constrain Flavobac-

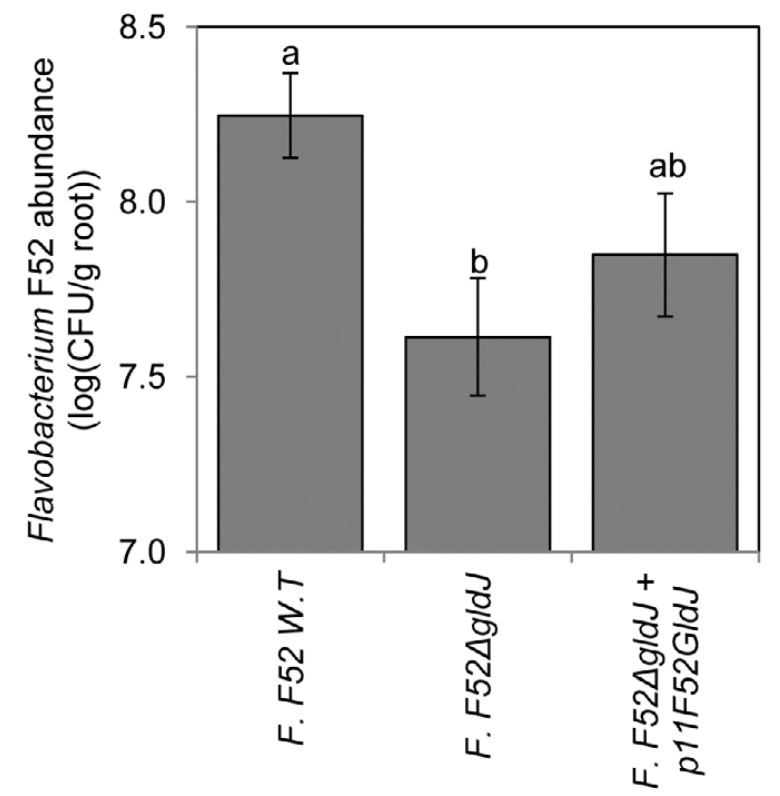

Fig. 4. Effect of gldJ disruption on root colonization. Surface-sterilized seeds were germinated for 14 days in sandy soil inoculated with approximately $10^{8}$ cells/g of soil. Then, 10 -fold serial dilutions of root homogenate were platted on casitone yeast extract agar plates with erythromycin at $100 \mu \mathrm{g} / \mathrm{ml}$. Triplicates of five independent experiments were performed. The statistical analysis was done by one-way analysis of variance with the Tukey-Kramer honestly significant difference test. Columns followed by a different letter are significantly different $(P<0.05)$. Error bars represent the standard error of the mean of five independent experiments. 
terium spp. to carbon-rich environments and explain their elevated abundance in the rhizosphere (Bodenhausen et al. 2013; Bulgarelli et al. 2012; Johansen and Binnerup 2002; Kolton et al. 2011; Manter et al. 2010; Lundberg et al. 2012; Schlaeppi et al. 2014), infected fish tissue (Bernardet and Bowman 2006; Sudheesh et al. 2012), and exopolymeric particles in aquatic ecosystems (Alonso et al. 2007; Giovannoni and Stingl 2005; Kirchman 2002).

Bacterial plant root colonization is a multistage process that involves recognition, movement toward root or seed attractants, and attachment. Once attached, persistence and propagation on plant roots is dependent on metabolic fitness and resistance to plant-protective mechanisms and microbial secondary metabolites. Motility is considered to be a prerequisite for rhizosphere competence and is key attribute of plant growth-promoting rhizobacteria (PGPR) (Compant et al. 2010; Rodriguez-Navarro et al. 2007; Sessitsch et al. 2012). Recent in vitro studies demonstrated that flavobacteria can glide over solid surfaces at speeds up to $5 \mu \mathrm{m} \mathrm{s}^{-1}$ (Jarrell and McBride 2008; McBride 2004; Nakane et al. 2013) and that the gliding-motility-T9SS complex is vital for flavobacterial surface attachment (Nelson et al. 2008; Rhodes et al. 2010; Shrivastava et al. 2013). Our hypothesis, which maintained that this unique gliding-motility-T9SS complex confers a competitive advantage in the rhizosphere, was supported by in planta analyses, which clearly demonstrated that this complex plays a role in seed adhesion (Fig. 3), plant root colonization (Fig. 4), and persistence of flavobacteria once attached to root surfaces (Fig. 5). The fish pathogen F. columare

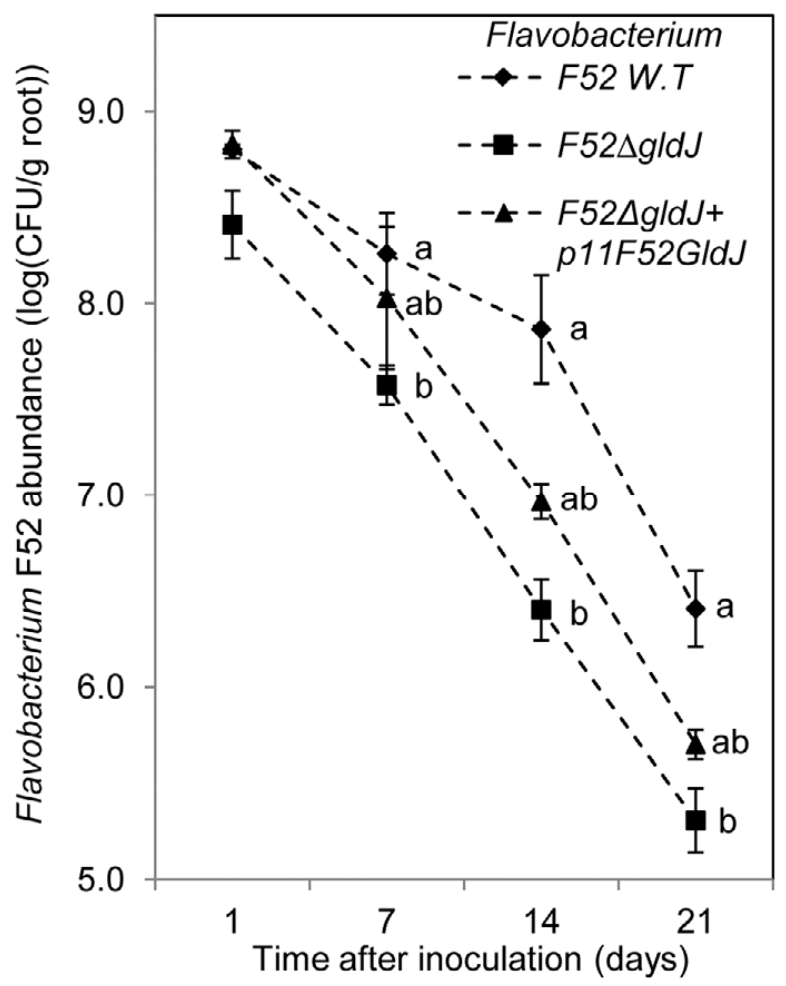

Fig. 5. Effect of gldJ disruption on root persistence. Roots of 40-day-old tomato seedlings were inoculated in bacterial suspensions (approximately $10^{8}$ to $10^{9} \mathrm{cells} / \mathrm{ml}$ ) for $30 \mathrm{~min}$ and transplanted into 0.25 -liter pots containing sterile sand for 21 days. Once a week, root systems of five independent plants were carefully collected, weighed, and homogenized in sterile saline. The 10-fold serial dilutions of roots homogenate were platted on casitone yeast extract agar plates with erythromycin $(100 \mu \mathrm{g} / \mathrm{ml})$. The statistical analysis was done by one-way analysis of variance with the Tukey-Kramer honestly significant difference test. Samples in each seed group followed by a different letter are significantly different $(P<0.05)$. Error bars represent the standard error of the mean of five independent experiments. exhibits a significant chemotactic response to catfish skin mucus facilitated by significant upregulation of gliding-motility genes expressed immediately after exposure to mucus (Klesius et al. 2008, 2010). In a similar manner, in the rhizosphere, plant exudates or mucilage may stimulate movement of flavobacteria from surrounding soil toward the roots by activating the glidingmotility-T9SS complex.

In order to survive and propagate in the rhizosphere, flavobacteria need to utilize plant-related organic matter. Recent comparative genomic analysis of the Flavobacterium strains revealed high abundance and diversity of genes involved in metabolism of plant-related carbohydrates such as xylose, arabinose, pectin, and rhamnogalacturonan that are exclusively associated with terrestrial plant hemicelluloses (Kolton et al. 2014). Some of these enzymes are predicted to be secreted through T9SS (Kolton et al. 2012, 2014) and, therefore, it is not surprising that the gliding-motility-T9SS complex mutants exhibited significantly lower rhizosphere survival than the corresponding nonmutant strains (Fig. 5).

Bacterial colonization of root surfaces may have beneficial effects on plant health by triggering or priming plant defense systems for more rapid or stronger defense response under future pathogen attacks (Lugtenberg and Kamilova 2009; Pieterse et al. 2012; Van der Ent et al. 2009; Van Loon 2007). Our analysis indicates strong correlations between Flavobacterium sp. strain $\mathrm{F} 52$ abundance in the tomato rhizosphere and resistance to canopy-applied $C$. michiganensis (Fig. 6). This positive effect was significantly reduced when gliding-motilityT9SS complex mutants were applied to the tomato roots (Fig. 6 ), suggesting a central role of this complex in both root colonization and stimulation of plant defense. Application of bacte-

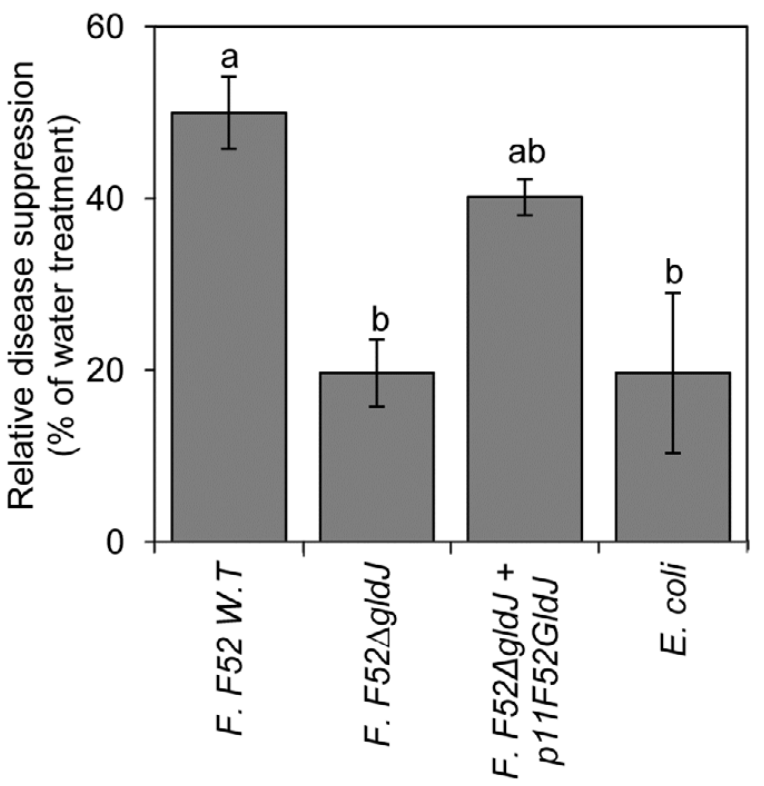

Fig. 6. Effect of gldJ disruption on pathogen suppression. Roots of 20day-old tomato seedlings were inoculated in bacterial suspensions (approximately $10^{8}$ to $10^{9}$ cells $/ \mathrm{ml}$ ) for $30 \mathrm{~min}$ and transplanted into 0.25 -liter pots containing sterile sand. Three days later, Clavibacter michiganensis subsp. michiganensis $\mathrm{Cmm} 32$ suspensions (approximately $10^{8}$ cells $/ \mathrm{ml}$ ) were sprayed onto tomato leaves. Estimation of disease propagation caused by $C$. michiganensis was observed during 3 weeks. The relative disease severity was calculated at the point that water-inoculated plants reached $70 \%$ of their maximal disease severity level. Five independent experiments with 15 to 20 plants for each inoculation treatment were performed. The statistical analysis was done by one-way analysis of variance with the Tukey-Kramer honestly significant difference test. Columns followed by a different letter are significantly different $(P<0.05)$. Error bars represent the standard error of the mean of five independent experiments. 
rial biocontrol agents or plant defense activators was proposed as a potential strategy to control and minimize $C$. michiganensis pathogenicity (Lanteigne et al. 2012; Van Loon 2007), and our results strongly support the potential of certain flavobacterial strains in this capacity. Recent in planta experiments reveled that HCN production by some Pseudomonas spp. has great potential for controlling bacterial canker of tomato (Lundberg et al. 2012). In vitro biochemical analysis of Flavobacterium sp. strain F52 revealed that it also produces $\mathrm{HCN}$ and possesses several other PGPR-related traits (Kolton et al. 2012, 2014). These characteristics, results from this study, and evidence from other studies indicating that some Flavobacterium isolates have biocontrol capabilities against other pathogens (Alexander and Stewart 2001; Gunasinghe and Karunaratne 2009; Hebbar et al. 1991; Sang and Kim 2012; Sang et al. 2008) suggest that they may be effective biocontrol agents against bacterial canker in the future. This study demonstrates that the flavobacterial gliding-motility-T9SS complex may play a central role in rhizosphere competence and that flavobacterial abundance on tomato root surfaces may be correlated with enhanced resistance to plant disease. In addition, it provides an initial link between the high abundance of flavobacteria in the rhizosphere and their unique physiology. Nevertheless, the contributions of the two gliding-motilityT9SS complex components in plant-microbe interactions are still not clear. Additional studies that specifically address the individual contribution of gliding-motility and T9SS functionality are required in order to determine their specific role in rhizosphere competence and plant protection.

\section{MATERIALS AND METHODS}

\section{Bacterial and bacteriophage strains, plasmids, and growth conditions.}

Flavobacterium sp. strain F52, recently isolated from the root of a greenhouse pepper (Kolton et al. 2012, 2014), was used as a model strain in this study, and gldJ mutants were derived from this strain. F. johnsoniae bacteriophages that recognize different determinants in the gliding-motility-T9SS complex $(\varphi C j 1, \varphi C j 13, \varphi C j 23, \varphi C j 28, \varphi C j 29, \varphi C j 42, \varphi C j 48$, and $\varphi C j 54)$ were also used in this study, as previously described (Braun and McBride 2005). The E. coli strains DH5 $\alpha$ MCR (Gibco BRL Life Technologies, Grand Island, NY, U.S.A.) and HB101 (Figurski and Helinski 1979) were used for genetic manipulations of gldJ genes. The gram-positive plant pathogen C. michiganensis subsp. michiganensis $\mathrm{Cmm} 32$, originally isolated from tomato plants (Kleitman et al. 2008), was used as a model foliar pathogen.

E. coli strains were grown in Luria-Bertani medium at $37^{\circ} \mathrm{C}$; Flavobacterium strains were grown in CYE medium (casitone at $10 \mathrm{~g} /$ liter, yeast extract at $5 \mathrm{~g} /$ liter, and $8 \mathrm{mM} \mathrm{MgSO}_{4}$ in 10 $\mathrm{mM}$ Tris buffer [pH 7.6]) at $28^{\circ} \mathrm{C}$, as previously described (McBride and Kempf 1996); and C. michiganensis was cultured on nutrient agar (NA) (Difco, Detroit) at $28^{\circ} \mathrm{C}$ for $72 \mathrm{~h}$.

Antibiotics were used at the indicated concentrations when needed: ampicillin at $100 \mu \mathrm{g} / \mathrm{ml}$, erythromycin at $100 \mu \mathrm{g} / \mathrm{ml}$, and tetracycline at $20 \mu \mathrm{g} / \mathrm{ml}$. Plasmids and primers used in this study are listed in Table 1 .

\section{Construction of gldJ mutant strains.}

The Flavobacterium sp. strain F52 gldJ mutant was constructed by initially amplifying a 283-bp fragment from the $\mathrm{N}$-terminal region and a 302-bp fragment from C-terminal region. The $\mathrm{N}$-terminal region was amplified using primers Fl52GldJBamF that contains a BamHI restriction site and three tandem stop codons at its the $5^{\prime}$ end, and Fl52GldHimR that contains a 22-bp complement to the $\mathrm{N}$-terminal region of gldJ and 21-bp complement to the C-terminal region, joined by three tandem stop codons. A 302-bp fragment of the C-terminal region was amplified using primers Fl52GldHimF (reverse complement primer of Fl52GldHimR) and Fl52GldJHindR that introduce three tandem stop codons followed by an HindIII restriction site at the $5^{\prime}$ end (Fig. 1A; Table 1). PCR reactions were performed using Phusion high-fidelity DNA

Table 1. Bacterial strains, plasmids, and primers used in this study

\begin{tabular}{|c|c|c|}
\hline Bacteria & Genotype or description $^{a}$ & Reference \\
\hline \multicolumn{3}{|l|}{ Strains } \\
\hline Flavobacterium sp. F52 & Wild type & Kolton et al. 2012, 2014 \\
\hline Flavobacterium sp. F52 $\Delta$ gldJ & gldJ disruption mutant $\left(\mathrm{Tet}^{\mathrm{r}}\right)$ & This study \\
\hline Clavibacter michiganensis subsp. & & \\
\hline michiganensis strain $\mathrm{Cmm} 32$ & Wild type & Kleitman et al. 2008 \\
\hline Escherichia coli strain DH5 $\alpha \mathrm{MCR}$ & $\begin{array}{l}\left.\mathrm{F}^{-} \text {mcrA } \Delta \text { (mrr-hsdRMS-mcrBC) } \varphi 80 \mathrm{~d} \text { lacZ } \Delta \mathrm{M} 15 \Delta \text { (lacZYA-argF }\right) \mathrm{U} 169 \text { endA1 } \\
\text { recAl deoR thi-1 supE44 } \lambda^{-} \text {gyrA96 relA1 }\end{array}$ & Gibco BRL Life Technologies \\
\hline E. coli strain HB101 & $\begin{array}{l}\lambda^{-} \text {recA13 proA2 leu lacY1 galK2 xyl-5 mtl-1 ara-14 } \mathrm{F}^{-} \mathrm{hsdS} 20\left(\mathrm{r}_{\mathrm{B}}{ }^{-} \mathrm{m}_{\mathrm{B}}{ }^{+}\right) \operatorname{supE44} \\
\text { rpsL20; Helper strain for triparental conjugation }\left(\mathrm{Kan}^{\mathrm{r}}\right)\end{array}$ & Figurski and Helinski 1979 \\
\hline \multicolumn{3}{|c|}{ T- } \\
\hline pRK2013 & Helper plasmid for triparental conjugation $\left(\operatorname{Kan}^{\mathrm{r}}\right)$ & Figurski and Helinski 1979 \\
\hline pLYL001 & Suicide vector used for insertional mutagenesis; $\mathrm{Amp}^{\mathrm{r}}\left(\mathrm{Tet}^{\mathrm{r}}\right)$ & Reeves et al. 1996 \\
\hline pF52JHim & $\begin{array}{l}\text { 611-bp Chimeric fragment of gldJ in pLYL001 for constructing gldJ disruption } \\
\text { mutant; } \mathrm{Amp}^{\mathrm{r}}\left(\mathrm{Tet}^{\mathrm{r}}\right)\end{array}$ & This study \\
\hline pCP11 & E. coli-Flavobacterium shuttle plasmid; Apr $\left(\right.$ Erm $\left.^{\mathrm{r}}\right)$ & McBride and Kempf 1996 \\
\hline p11F52GldJ & pCP11 carrying gldJ Amp ${ }^{\mathrm{r}}\left(\mathrm{Erm}^{\mathrm{r}}\right)$ & This study \\
\hline \multicolumn{3}{|l|}{ Primers ${ }^{\mathrm{b}}$} \\
\hline F152GldJBamF & 5'-ATAGGATCCTAATAGTGA GATGTTATGCACGATTGGA & This study \\
\hline \multirow[t]{2}{*}{ Fl52GldHimR } & 5'-CTTATCACCATCTCTGTAGTTTCACTATTA & \\
\hline & TTGAATCCAGTTCACACCAACT & This study \\
\hline \multirow[t]{2}{*}{ F152GldHimF } & 5'-AGTTGGTGTGAACTGGATTCAATAATAGTGA & \\
\hline & AACTACAGAGATGGTGATAAG & This study \\
\hline Fl52GldJHindR & 5'-TATAAGCTTTCACTATTA GACATTGCACATCTGAAGCC & This study \\
\hline F52gldJcomplFor & 5'-ACTACTAGTGCTTCATCTGTTAAAAAGGCG & This study \\
\hline F52gldJcomplRev & 5'-ACT $\overline{C C C G G G T C A A T A G A C A G A G A A C T G C A C ~}$ & This study \\
\hline
\end{tabular}


polymerase (New England Biolabs, Beverly MA, U.S.A.) with 30 cycles of denaturation at $94^{\circ} \mathrm{C}$ for $30 \mathrm{~s}$, annealing at $53^{\circ} \mathrm{C}$ for $30 \mathrm{~s}$, and elongation at $72^{\circ} \mathrm{C}$ for $20 \mathrm{~s}$. Next, the two amplified fragments were joined by PCR reaction (30 cycles of denaturation at $94^{\circ} \mathrm{C}$ for $30 \mathrm{~s}$, annealing at $53^{\circ} \mathrm{C}$ for $30 \mathrm{~s}$, and elongation at $72^{\circ} \mathrm{C}$ for $45 \mathrm{~s}$ ) using Fl52GldJBamF and Fl52GldJHindR. The generated amplicon was digested with Bam HI and HindIII (New England Biolabs) and inserted into suicide plasmid pLYL001 (Reeves et al. 1996), which had been digested with the same enzymes, to generate pF52JHim (Fig. 1A; Table 1). This plasmid was transformed into E. coli DH5 $\alpha$ cells by standard heat-shock transformation. The subsequent Flavobacterium sp. strain F52 gldJ disruption mutation was then generated by triparental mating using E. coli $\mathrm{DH} 5 \alpha$ carrying pF52JHim and the helper strain E. coli HB101 carrying pRK2013, as previously described (McBride and Kempf 1996). Validation of insertion of the chimeric gldJ into the chromosomal gldJ gene was confirmed by PCR screening of tetracycline-resistant colonies and by whole-genome sequencing (data not shown).

\section{Construction of gldJ complement strains.}

For complementation studies, a 2.077-bp PCR product containing the WT gldJ open reading frame, a 220-bp upstream region including the promoter region, and a 170-bp transcriptional termination region were obtained using the F52gldJcomplFor and F52gldJcomplRev primers, which insert SpeI and XmaI restriction sites at the ends of the PCR product (Fig. 1B; Table 1). PCR was achieved as follows: 30 cycles of denaturation at $94^{\circ} \mathrm{C}$ for $30 \mathrm{~s}$, annealing at $56^{\circ} \mathrm{C}$ for $30 \mathrm{~s}$, and elongation at $72^{\circ} \mathrm{C}$ for $90 \mathrm{~s}$. The resulting PCR product was digested with SpeI and XmaI (New England Biolabs) and inserted to the shuttle vector pCP11 (McBride and Kempf 1996), which had been digested with the same enzymes to generate p11F52GldJ (Fig. 1B; Table 1). Inserts of p11F52GldJ were sequenced and transformed into gldJ-disrupted Flavobacterium F52 strains by electroporation, as previously described (McBride and Kempf 1996), to generate complement strains.

\section{Phenotypic verification of gldJ mutants.}

Flavobacterium strains were grown in CYE medium with appropriate antibiotics. Each stationary-phase culture $(1 \mathrm{ml})$ was collected by centrifugation at $8,000 \times g$ for $3 \mathrm{~min}$, washed with $1 \mathrm{ml}$ of a TC buffer (10 mM Tris and $8 \mathrm{mM} \mathrm{CaCl}_{2}$ [pH 7.3]), and suspended in $0.5 \mathrm{ml}$ of TC buffer (McBride et al. 2003).

Growth of WT, mutant, and complement strains with and without pCP11 plasmids and antibiotics was monitored in CYE medium at different temperatures $\left(20,25\right.$, and $\left.30^{\circ} \mathrm{C}\right)$ by measuring optical density values (optical density at $600 \mathrm{~nm}\left[\mathrm{OD}_{600}\right]$ ) of eight independent cultures during 24-h growth periods.

Gliding motility was observed with a Leica MZFLIII stereomicroscope (Leica Microsystems, Heerburg, Germany) coupled to a Nikon DS-Fi1 CCD camera operated by a Nikon digital sight system (Nikon Instruments, Melville, NY, U.S.A.). Suspended bacteria ( $2 \mu \mathrm{l}$; approximately $4 \times 10^{7}$ cells $)$ were spotted on PY2 agar (peptone at 2 g/liter, yeast extract at 0.5 $\mathrm{g} /$ liter, and agar at $10 \mathrm{~g} / \mathrm{liter}[\mathrm{pH} 7.3]$ ) (Agarwal et al. 1997) and incubated at $30^{\circ} \mathrm{C}$ for 24 to $48 \mathrm{~h}$.

Chitin utilization was observed as previously described (McBride et al. 2003). Briefly, $3 \mathrm{ml}$ of $2 \%$ chitin slurry was added on top of solid PY2 agar medium plates and allowed to dry. Suspended bacteria $(2 \mu \mathrm{l})$ were spotted on PY2-chitin agar plates and incubated at $30^{\circ} \mathrm{C}$ for up to 6 days in a moist chamber.

Flavobacterial bacteriophages $\varphi C j 1, \varphi C j 13, \varphi C j 23, \varphi C j 28$, $\varphi C j 29, \varphi C j 42, \varphi C j 48$, and $\varphi C j 54$ that recognize determinants in the gliding-motility-T9SS complex (Braun and McBride
$2005)$ were applied to validate gldJ mutant strains. Sensitivity to $F$. johnsoniae bacteriophages was performed in the laboratory of M. J. McBride, as previously described (Hunnicutt and McBride 2000).

\section{Flavobacterium adhesion to tomato seed.}

The capacity of Flavobacterium sp. strain F52, Flavobacterium sp. strain F52 gldJ mutant, and complement strains to adhere to tomato seed surfaces was determined based on previously described assays (Espinosa-Urgel and Ramos 2004; Shankar et al. 2011). Tomato seed (S. lycopersicum. 'Fantasia' [1125]; Hazera Genetics Ltd., Berorim, Israel) were initially surface sterilized by soaking for $5 \mathrm{~min}$ in $20 \%$ commercial bleach (approximately 1\% sodium hypochlorite) followed by $10 \mathrm{~min}$ of incubation in $70 \%$ ethanol and then were thoroughly rinsed three times with sterile tap water.

Flavobacterium WT, mutant, and complement strains were grown under optimal conditions $\left(25\right.$ to $28^{\circ} \mathrm{C}$ and $\left.220 \mathrm{rpm}\right)$ in CYE medium with the appropriate selection marker to $\mathrm{OD}_{600}=$ 0.8 , which is equivalent to approximately $7 \times 10^{8}$ cells $/ \mathrm{ml}$. Based on unpublished preliminary experiments, this value represents late exponential phase. Seed were immersed in flavobacterial strains suspensions prepared in $10 \mathrm{mM} \mathrm{MgSO}_{4}$. Ten seed were recovered at different time points $(1,5,10,20$, and $30 \mathrm{~min})$ and washed using three different intensity levels in saline $(\mathrm{NaCl}$ at $8.5 \mathrm{~g} /$ liter) for $30 \mathrm{~s}$ to remove reversibly adhered cells (Espinosa-Urgel and Ramos 2004; Shankar et al. 2011). For low-intensity-level washing, seed were resuspended in $5 \mathrm{ml}$ of saline; for medium-intensity-level washing, seed were vortexed in $5 \mathrm{ml}$ of saline; and for high-intensity-level washing, seed were vortexed in $5 \mathrm{ml}$ of saline with five glass beads $(3 \mathrm{~mm}$ in diameter). Washed, inoculated seed were transferred to a fresh tube containing $5 \mathrm{ml}$ of saline and five glass beads $(3 \mathrm{~mm}$ in diameter) and vortexed for $5 \mathrm{~min}$ to dislodge tightly adhered cells. At this stage, 10-fold serial dilutions of the bacterial suspensions were transferred to CYE-agar plates supplemented with erythromycin at $100 \mu \mathrm{g} / \mathrm{ml}$ as a selection marker. The abundance of the flavobacterial strains was calculated and expressed as $\log [\mathrm{CFU} / \mathrm{seed}]$. Five independent experiments with triplicates for each time point were performed. All values reported are means of these measurements.

\section{Flavobacterium root surface colonization.}

Root adhesion of the flavobacterial strains was tested using a modified version of the previously described sand-tube method (Ahmad and Baker 1987; Scher et al. 1984). Briefly, $40 \mathrm{ml}$ of Flavobacterium cultures were grown as described above and mixed with $300 \mathrm{~g}$ of dry sterilized sand. Polypropylene centrifuge tubes $(50-\mathrm{ml})$ were filled with $20 \mathrm{ml}$ of sterile perlite soaked with $10 \mathrm{ml}$ of sterile standard 5:3:8 NPK fertilizer, and overlaid with bacterial-amended sand $\left(10^{8}\right.$ cells/g soil) sown with three surface-sterilized tomato seed. The tubes were covered with parafilm, inserted into plastic bags, and placed in an experimental pest- and disease-free plant growth chamber. No water or NPK fertilizer was added to the tubes after seed germination. Once a week over the course of 3 weeks, the tubes were opened and roots were carefully excised, weighed, and homogenized in sterile saline. Then, 10-fold serial dilutions of the homogenate were performed, aliquots of $0.1 \mathrm{ml}$ were platted on CYE-agar plates with the appropriate antibiotic selection marker, and the abundance of flavobacterial strains on root surfaces was expressed as $\log [\mathrm{CFU} / \mathrm{g}$ of fresh root weight].

\section{Flavobacterium root surface persistence.}

The flavobacterial strains were grown under optimal condition (25 to $28^{\circ} \mathrm{C}$ and $220 \mathrm{rpm}$ ) for $24 \mathrm{~h}$ in CYE medium 
with the appropriate selection marker and diluted with fresh sterile CYE medium to $\mathrm{OD}_{600}=0.8$, equivalent to approximately $7 \times 10^{8}$ cells $/ \mathrm{ml}$. Roots from 20 -day-old tomato seedlings (S. lycopersicum 1125) obtained from a commercial nursery (Hishtil, Ashkelon, Israel) were carefully washed under a stream of tap water to remove potting media, inoculated in flavobacterial suspensions for $30 \mathrm{~min}$, and transplanted into 0.25 -liter pots containing sterile sand. Plants were transferred to an experimental pest- and disease-free greenhouse for 21 days, as previously described. Once a week, root systems of five independent plants initially inoculated with WT, gldJ mutant, and complement strains were carefully collected, weighed, and homogenized in sterile saline and platted on CYE-agar plates with appropriate antibiotic selection markers, as described above. Finally, abundance of flavobacterial strains on root surfaces was expressed as $\log [\mathrm{CFU} / \mathrm{g}$ fresh root weight].

\section{Flavobacterium stimulation of plant defense.}

Tomato seedling roots were inoculated with flavobacterial strains, E. coli DH5 $\alpha \mathrm{MCR}$, or water as described in the Flavobacterium root surface persistence section above. The tomato pathogen $C$. michiganensis subsp. michiganensis $\mathrm{Cmm} 32$ was cultured on NA (Difco) plates at $28^{\circ} \mathrm{C}$ for $72 \mathrm{~h}$. C. michiganensis cells were washed and suspended in $2 \mathrm{ml}$ of distilled water and the resulting suspension was adjusted to $\mathrm{OD}_{600}=$ 0.5 , which corresponds to $10^{9}$ cell $/ \mathrm{ml}$. This suspension was diluted to a final concentration of $10^{8}$ cells $/ \mathrm{ml}$ (Sharabani et al. 2013) and sprayed onto tomato leaves 3 days after initial root inoculation. Five independent experiments with 15 to 20 plants for each inoculation treatment were performed; all experiments included a control treatment in which water was sprayed instead of $C$. michiganensis. Disease propagation caused by $C$. michiganensis was evaluated for the duration of a 3-week period by counting the white blisters on each plant canopy (i.e., symptoms of localized infections that were apparent on the leaf blades). A scoring system was used to estimate disease severity based on the number of blisters $(0$ blisters $=0 ; 1$ to 3 blisters $=2 ; 4$ to 10 blisters $=7 ; 11$ to 20 blisters $=15 ; 21$ to 50 blisters $=35$; more than 50 blisters $=75$ ). Finally, the disease severity was calculated based on the area under the disease progress curve (AUDPC).

\section{Statistical analysis.}

Due to large variations in disease severity between independent experiments, we calculated the relative disease severity at the point that water-inoculated root plants reached $70 \%$ of their maximal disease level. The relative disease severity $($ RDS $)$ was calculated as RDS $=100-\left[\left(\right.\right.$ AUDPC $\left._{\text {(bacteria treatment })}\right]$ $\left.\mathrm{AUDPC}_{\text {(water treatment) }}\right) \times 100$ ], where AUDPC represents the previously defined area under the disease propagation curve.

The statistical differences between treatments in all of the experiments were determined by one-way analysis of variance with the Tukey-Kramer honestly significant difference test at $P \leq 0.05$ using the SPSS 18 software package (SPSS Inc., Chicago). Basic analyses of the protein localizations were predicted with PSORTb v3.0 webserver (Yu et al. 2010).

\section{ACKNOWLEDGMENTS}

This work was supported by a grant from the Chief Scientist of the Ministry of Agriculture and Rural Development of Israel, project number 301-0693-10. We thank M. J. McBride from the University of WisconsinMilwaukee for generously providing plasmids and for invaluable advice, Y. Zhu for performing bacteriophage resistance assays, and S. Green from the University of Illinois at Chicago for sequencing and assembly of the gldJ mutant strain.

\section{LITERATURE CITED}

Agarwal, S., Hunnicutt, D. W., and McBride, M. J. 1997. Cloning and characterization of the Flavobacterium johnsoniae (Cytophaga johnsonae) gliding motility gene, gldA. Proc. Natl. Acad. Sci. U.S.A. 94:12139-12144.

Ahmad, J. S., and Baker, R. 1987. Rhizosphere competence of Trichoderma harzianum. Phytopathology 77:182-189.

Alexander, B. J. R., and Stewart, A. 2001. Glasshouse screening for biological control agents of Phytophthora cactorum on apple (Malus domestica). N. Z. J. Crop Hortic. Sci. 29:159-169.

Alonso, C., Warnecke, F., Amann, R., and Pernthaler, J. 2007. High local and global diversity of Flavobacteria in marine plankton. Environ. Microbiol. 9:1253-1266.

Barret, M., Morrissey, J. P., and O'Gara, F. 2011. Functional genomics analysis of plant growth-promoting rhizobacterial traits involved in rhizosphere competence. Biol. Fertil. Soils 47:729-743.

Berendsen, R. L., Pieterse, C. M. J., and Bakker, P. A. H. M. 2012. The rhizosphere microbiome and plant health. Trends Plant Sci. 17:478-486.

Bernardet, J. F., and Bowman, J. P. 2006. The genus Flavobacterium. Pages 481-531 in: The Prokaryotes: A Handbook on the Biology of Bacteria. M. Dworkin, S. Falkow, E. Rosenberg, K. H. Schleifer, and E. Stackebrandt, eds. Springer, New York.

Bodenhausen, N., Horton, M. W., and Bergelson, J. 2013. Bacterial communities associated with the leaves and the roots of Arabidopsis thaliana. PLoS One 8:e56329. Published online.

Braun, T. F., and McBride, M. J. 2005. Flavobacterium johnsoniae GldJ is a lipoprotein that is required for gliding motility. J. Bacteriol. 187:26282637.

Bulgarelli, D., Rott, M., Schlaeppi, K., van Themaat, E. V. L., Ahmadinejad, N., Assenza, F., Rauf, P., Huettel, B., Reinhardt, R., Schmelzer, E., Peplies, J., Gloeckner, F. O., Amann, R., Eickhorst, T., and SchulzeLefert, P. 2012. Revealing structure and assembly cues for Arabidopsis root-inhabiting bacterial microbiota. Nature 488:91-95.

Carlton, W. M., Braun, E. J., and Gleason, M. L. 1998. Ingress of Clavibacter michiganensis subsp. michiganensis into tomato leaves through hydathodes. Phytopathology 88:525-529.

Choudhary, D. K., and Johri, B. N. 2009. Interactions of Bacillus spp. and plants-with special reference to induced systemic resistance (ISR). Microbiol. Res. 164:493-513.

Compant, S., Clement, C., and Sessitsch, A. 2010. Plant growth-promoting bacteria in the rhizo- and endosphere of plants: Their role, colonization, mechanisms involved and prospects for utilization. Soil Biol. Biochem. 42:669-678.

Dennis, P. G., Miller, A. J., and Hirsch, P. R. 2010. Are root exudates more important than other sources of rhizodeposits in structuring rhizosphere bacterial communities? FEMS (Fed. Eur. Microbiol. Soc.) Microbiol. Ecol. 72:313-327.

Eichenlaub, R., and Gartemann, K. H. 2011. The Clavibacter michiganensis subspecies: Molecular investigation of gram-positive bacterial plant pathogens. Annu. Rev. Phytopathol. 49:445-464.

Espinosa-Urgel, M., and Ramos, J. L. 2004. Cell density-dependent gene contributes to efficient seed colonization by Pseudomonas putida KT2440. Appl. Environ. Microbiol. 70:5190-5198.

Espinosa-Urgel, M., Kolter, R., and Ramos, J. L. 2002. Root colonization by Pseudomonas putida: Love at first sight. Microbiology 148:341-343.

Figurski, D. H., and Helinski, D. R. 1979. Replication of an origin-containing derivative of plasmid RK2 dependent on a plasmid function provided in trans. Proc. Natl. Acad. Sci. U.S.A. 76:1648-1652.

Giovannoni, S. J., and Stingl, U. 2005. Molecular diversity and ecology of microbial plankton. Nature 437:343-348.

Gunasinghe, W. K. R. N., and Karunaratne, A. M. 2009. Interactions of Colletotrichum musae and Lasiodiplodia theobromae and their biocontrol by Pantoea agglomerans and Flavobacterium sp. in expression of crown rot of "Embul" banana. Biocontrol 54:587-596.

Haggag, W. M., and Timmusk, S. 2008. Colonization of peanut roots by biofilm-forming Paenibacillus polymyxa initiates biocontrol against crown rot disease. J. Appl. Microbiol. 104:961-969.

Hebbar, P., Berge, O., Heulin, T., and Singh, S. P. 1991. Bacterial antagonists of sunflower (Helianthus annuus L.) fungal pathogens. Plant Soil 133:131-140.

Hunnicutt, D. W., and McBride, M. J. 2000. Cloning and characterization of the Flavobacterium johnsoniae gliding-motility genes gldB and gldC. J. Bacteriol. 182:911-918.

Jarrell, K. F., and McBride, M. J. 2008. The surprisingly diverse ways that prokaryotes move. Nat. Rev. Microbiol. 6:466-476.

Johansen, J. E., and Binnerup, S. J. 2002. Contribution of Cytophaga-like bacteria to the potential of turnover of carbon, nitrogen, and phosphorus by bacteria in the rhizosphere of barley (Hordeum vulgare L.). Microb. Ecol. 43:298-306. 
Kirchman, D. L. 2002. The ecology of Cytophaga-Flavobacteria in aquatic environments. FEMS (Fed. Eur. Microbiol. Soc.) Microbiol. Ecol. 39:91-100.

Kleitman, F., Barash, I., Burger, A., Iraki, N., Falah, Y., Sessa, G., Weinthal, D., Chalupowicz, L., Gartemann, K. H., Eichenlaub, R., and ManulisSasson, S. 2008. Characterization of a Clavibacter michiganensis subsp. michiganensis population in Israel. Eur. J. Plant Pathol. 121:463475 .

Klesius, P. H., Shoemaker, C. A., and Evans, J. J. 2008. Flavobacterium columnare chemotaxis to channel catfish mucus. FEMS (Fed. Eur. Microbiol. Soc.) Microbiol. Lett. 288:216-220.

Klesius, P. H., Pridgeon, J. W., and Aksoy, M. 2010. Chemotactic factors of Flavobacterium columnare to skin mucus of healthy channel catfish (Ictalurus punctatus). FEMS (Fed. Eur. Microbiol. Soc.) Microbiol. Lett. 310:145-151.

Kolton, M., Harel, Y. M., Pasternak, Z., Graber, E. R., Elad, Y., and Cytryn, E. 2011. Impact of biochar application to soil on the root-associated bacterial community structure of fully developed greenhouse pepper plants. Appl. Environ. Microbiol. 77:4924-4930.

Kolton, M., Green, S. J., Harel, Y. M., Sela, N., Elad, Y., and Cytryn, E. 2012. Draft genome sequence of Flavobacterium sp. strain F52, isolated from the rhizosphere of bell pepper (Capsicum annuиm L. cv. Maccabi). J. Bacteriol. 194:5462-5463.

Kolton, M., Sela, N., Elad, Y., and Cytryn, E. 2014. Comparative genomic analysis indicates that niche adaptation of terrestrial Flavobacteria is strongly linked to plant glycan metabolism. PLoS One 9. doi:10.1371/annotation/3eafbdc9-374a-447a-852b-7a64503b8ccb. Published online.

Lanteigne, C., Gadkar, V. J., Wallon, T., Novinscak, A., and Filion, M. 2012. Production of DAPG and HCN by Pseudomonas sp. LBUM300 contributes to the biological control of bacterial canker of tomato. Phytopathology 102:967-973.

Lugtenberg, B., and Kamilova, F. 2009. Plant-growth-promoting rhizobacteria. Annu. Rev. Microbiol. 63:541-556.

Lundberg, D. S., Lebeis, S. L., Paredes, S. H., Yourstone, S., Gehring, J., Malfatti, S., Tremblay, J., Engelbrektson, A., Kunin, V., del Rio, T. G., Edgar, R. C., Eickhorst, T., Ley, R. E., Hugenholtz, P., Tringe, S. G., and Dangl, J. L. 2012. Defining the core Arabidopsis thaliana root microbiome. Nature 488:86-90.

Manter, D. K., Delgado, J. A., Holm, D. G., and Stong, R. A. 2010. Pyrosequencing reveals a highly diverse and cultivar-specific bacterial endophyte community in potato roots. Microb. Ecol. 60:157-166.

McBride, M. J. 2004. Cytophaga-flavobacterium gliding motility. J. Mol Microbiol. Biotechnol. 7:63-71

McBride, M. J., and Kempf, M. J. 1996. Development of techniques for the genetic manipulation of the gliding bacterium Cytophaga johnsonae. J. Bacteriol. 178:583-590.

McBride, M. J., and Zhu, Y. T. 2013. Gliding motility and Por secretion system genes are widespread among members of the phylum Bacteroidetes. J. Bacteriol. 195:270-278.

McBride, M. J., Braun, T. F., and Brust, J. L. 2003. Flavobacterium johnsoniae GldH is a lipoprotein that is required for gliding motility and chitin utilization. J. Bacteriol. 185:6648-6657.

Mendes, R., Kruijt, M., de Bruijn, I., Dekkers, E., van der Voort, M., Schneider, J. H. M., Piceno, Y. M., DeSantis, T. Z., Andersen, G. L., Bakker, P. A. H. M., and Raaijmakers, J. M. 2011. Deciphering the rhizosphere microbiome for disease-suppressive bacteria. Science 332:1097-1100

Mendes, R., Garbeva, P., and Raaijmakers, J. M. 2013. The rhizosphere microbiome: Significance of plant beneficial, plant pathogenic, and human pathogenic microorganisms. FEMS (Fed. Eur. Microbiol. Soc.) Microbiol. Rev. 37:634-663.

Nakane, D., Sato, K., Wada, H., McBride, M. J., and Nakayama, K. 2013. Helical flow of surface protein required for bacterial gliding motility. Proc. Natl. Acad. Sci. U.S.A. 110:11145-11150.

Nelson, S. S., Bollampalli, S., and McBride, M. J. 2008. SprB is a cell surface component of the Flavobacterium johnsoniae gliding motility machinery. J. Bacteriol. 190:2851-2857.

Peterson, S. B., Dunn, A. K., Klimowicz, A. K., and Handelsman, J. 2006. Peptidoglycan from Bacillus cereus mediates commensalism with rhizosphere bacteria from the Cytophaga-Flavobacterium group. Appl. Environ. Microbiol. 72:5421-5427.

Pieterse, C. M. J., Van der Does, D., Zamioudis, C., Leon-Reyes, A., and Van Wees, S. C. M. 2012. Hormonal modulation of plant immunity. Annu. Rev. Cell Dev. Biol. 28:489-521.

Reeves, A. R., D'Elia, J. N., Frias, J., and Salyers, A. A. 1996. A Bacteroides thetaiotaomicron outer membrane protein that is essential for utilization of maltooligosaccharides and starch. J. Bacteriol. 178:823830.

Rhodes, R. G., Samarasam, M. N., Shrivastava, A., van Baaren, J. M., Pochiraju, S., Bollampalli, S., and McBride, M. J. 2010. Flavobacterium johnsoniae gldN and gldO are partially redundant genes required for gliding motility and surface localization of SprB. J. Bacteriol. 192:1201-1211.

Rodriguez-Navarro, D. N., Dardanelli, M. S., and Ruiz-Sainz, J. E. 2007. Attachment of bacteria to the roots of higher plants. FEMS (Fed. Eur. Microbiol. Soc.) Microbiol. Lett. 272:127-136.

Ryu, C. M., Farag, M. A., Hu, C. H., Reddy, M. S., Kloepper, J. W., and Pare, P. W. 2004. Bacterial volatiles induce systemic resistance in Arabidopsis. Plant Physiol. 134:1017-1026.

Sang, M. K., and Kim, K. D. 2012. The volatile-producing Flavobacterium johnsoniae strain GSE09 shows biocontrol activity against Phytophthora capsici in pepper. J. Appl. Microbiol. 113:383-398.

Sang, M. K., Chun, S. C., and Kim, K. D. 2008. Biological control of Phytophthora blight of pepper by antagonistic rhizobacteria selected from a sequential screening procedure. Biol. Control 46:424-433.

Sato, K., Naito, M., Yukitake, H., Hirakawa, H., Shoji, M., McBride, M. J. Rhodes, R. G., and Nakayama, K. 2010. A protein secretion system linked to bacteroidete gliding motility and pathogenesis. Proc. Natl. Acad. Sci. U.S.A. 107:276-281.

Scher, F. M., Ziegle, J. S., and Kloepper, J. W. 1984. A method for assessing the root-colonizing capacity of bacteria on maize. Can. J. Microbiol. 30:151-157.

Schlaeppi, K., Dombrowski, N., Oter, R. G., van Themaat, E. V. L., and Schulze-Lefert, P. 2014. Quantitative divergence of the bacterial root microbiota in Arabidopsis thaliana relatives. Proc. Natl. Acad. Sci. U.S.A. 111:585-592

Sessitsch, A., Hardoim, P., Doring, J., Weilharter, A., Krause, A., Woyke, T., Mitter, B., Hauberg-Lotte, L., Friedrich, F., Rahalkar, M., Hurek, T., Sarkar, A., Bodrossy, L., van Overbeek, L., Brar, D., van Elsas, J. D., and Reinhold-Hurek, B. 2012. Functional characteristics of an endophyte community colonizing rice roots as revealed by metagenomic analysis. Mol. Plant-Microbe Interact. 25:28-36.

Shankar, M., Ponraj, P., Ilakkiam, D., and Gunasekaran, P. 2011. Root colonization of a rice growth promoting strain of Enterobacter cloacae. J. Basic Microbiol. 51:523-530.

Sharabani, G., Manulis-Sasson, S., Borenstein, M., Shulhani, R., Lofthouse, M., Chalupowicz, L., and Shtienberg, D. 2013. The significance of guttation in the secondary spread of Clavibacter michiganensis subsp. michiganensis in tomato greenhouses. Plant Pathol. 62:578-586.

Shipman, J. A., Berleman, J. E., and Salyers, A. A. 2000. Characterization of four outer membrane proteins involved in binding starch to the cell surface of Bacteroides thetaiotaomicron. J. Bacteriol. 182:5365-5372.

Shrivastava, A., Johnston, J. J., van Baaren, J. M., and McBride, M. J. 2013. Flavobacterium johnsoniae GldK, GldL, GldM, and SprA are required for secretion of the cell surface gliding motility adhesins SprB and RemA. J. Bacteriol. 195:3201-3212.

Sudheesh, P. S., Al-Ghabshi, A., Al-Mazrooei, N., and Al-Habsi, S. 2012. Comparative pathogenomics of bacteria causing infectious diseases in fish. Int. J. Evol. Biol. http://dx.doi.org/10.1155/2012/457264. Published online.

Van der Ent, S., Van Wees, S. C. M., and Pieterse, C. M. J. 2009. Jasmonate signaling in plant interactions with resistance-inducing beneficial microbes. Phytochemistry 70:1581-1588.

Van Loon, L. C. 2007. Plant responses to plant growth-promoting rhizobacteria. Eur. J. Plant Pathol. 119:243-254.

Werner, N. A., Fulbright, D. W., Podolsky, R., Bell, J., and Hausbeck, M. K. 2002. Limiting populations and spread of Clavibacter michiganensis subsp. michiganensis on seedling tomatoes in the greenhouse. Plant Dis. $86: 535-542$

Xu, J., Bjursell, M. K., Himrod, J., Deng, S., Carmichael, L. K., Chiang, H. C., Hooper, L. V., and Gordon, J. I. 2003. A genomic view of the human-Bacteroides thetaiotaomicron symbiosis. Science 299:20742076

Yu, N. Y., Wagner, J. R., Laird, M. R., Melli, G., Rey, S., Lo, R., Dao, P., Sahinalp, S. C., Ester, M., Foster, L. J., and Brinkman, F. S. L. 2010 PSORTb 3.0: Improved protein subcellular localization prediction with refined localization subcategories and predictive capabilities for all prokaryotes. Bioinformatics 26:1608-1615.

\section{AUTHOR-RECOMMENDED INTERNET RESOURCE}

PSORTb v3.0 webserver: www.psort.org/psortb 